\title{
ASEAN Journal of Science and Engineering
}

Journal homepage: http://ejournal.upi.edu/index.php/AJSE/

\section{How to Calculate Crystallite Size from X-Ray Diffraction (XRD) using Scherrer Method}

Siti Fatimah, Risti Ragadhita, Dwi Fitria Al Husaeni, Asep Bayu Dani Nandiyanto*

Fakultas Pendidikan Matematika dan IImu Pengetahuan Alam, Universitas Pendidikan Indonesia, Indonesia Correspondence: E-mail: nandiyanto@upi.edu

\section{ABSTRACT}

X-Ray Diffraction (XRD) has been developed to analyze a crystal structure in the material. XRD is then improved for determining and identifying the presence of a compound, crystallinity, and crystal properties. XRD works by observing the ray refraction pattern as a result of the beam being refracted by a material that has an atomic arrangement in its crystal lattice. Until now, there is less information regarding detailed information on how to read the XRD spectrum and peak. This study aims to demonstrate how to calculate and interpret the crystallite size based on the XRD spectra. The step-by-step method in the calculation based on the XRD data is presented, which can help especially students and first-time users in understanding XRD results. This study is prospective to be used as standard information on how to read and interpret XRD spectra.
ARTICLE INFO

Article History:

Submitted/Received 12 Jun 2021

First revised $13 \mathrm{Jul} 2021$

Accepted 13 Sep 2021

First available online $15 \mathrm{Sep} 2021$

Publication date 01 Mar 2022

Keyword:

Analysis,

Engineering,

Material,

Solid-state,

Students,

$X$-ray diffraction. 


\section{INTRODUCTION}

X-Ray Diffraction (XRD) is a method or instrument used to determine the atomic and molecular structure of a crystal by diffracting a beam of X-rays in all directions. In general, the function of the XRD tool is to identify and analyze the phase of a material, in the form of powder or solid from inorganic samples, in the form of polycrystalline and amorphous. XRD can be used for qualitative and quantitative analysis (Smith et al., 1987; Zhou et al., 2018). In the quantitative analysis, the data presented is including of two theta angels, peak intensity, and the amount of lattice constant. For qualitative analysis, the data includes phase analysis, which can be in the form of identification of the type of phase, phase composition (percentage), crystallite size, orientation, and others (Monshi et al., 2012).

In the analysis using XRD instruments, the basic principle of XRD is to diffract light through the crystal slit. Diffraction of light by lattices or crystals can occur if the diffraction comes from a radius that has a wavelength equivalent to the distance between atoms, which is about 1 Angstrom. The radiation is used in the form of X-ray radiation, electrons, and neutrons. X-ray is a photon with high energy which has a wavelength ranging from 0.5 up to 2.5 Amstrong. When an X-ray beam interacts with a material, some of the beams will be absorbed, transmitted, and some of it is scattered diffracted. This scattered diffraction is what XRD detects. The scattered X-ray beam is canceled each other out because the phases are different and some are mutually reinforcing because the phase is the same. $X$-ray beams that reinforce each other are called diffraction beams. When X-rays are fired at the crystal lattice of the material to be tested, the rays are diffracted and form certain patterns called fingerprints (Hakim et al., 2019; Bunaciu et al., 2015). The application of this XRD instrument is very widely used. This XRD instrument is most often used for the identification of unknown crystalline materials (e.g., minerals, inorganic compounds). One of them is that the characterization of unknown materials using XRD instruments is very useful for studies in geology, environmental science, materials science, engineering, and biology. Other applications of XRD instruments are the characterization of crystalline materials, identification of fine-grained minerals, determination of unit cell dimensions, and measurement of sample purity (Bunaciu et al., 2015; Alexander \& Klug, 1948, Zhou et al., 2018).

There are many explanations about how to analyze XRD. However, in general, these articles have not explained in detail the steps on how to obtain data from the results of material characterization with XRD instruments. A detailed understanding of XRD analysis is necessary and important for every student and scientist, especially those who research the field of chemicals. Therefore, the focus of this research is to discuss and explain how to read the characterization results of the XRD instrument. In particular, in calculating the crystallite size. The results of the XRD analysis were also compared with the available literature. This study is equipped with steps on how to read XRD. In addition, this study is also equipped with a review of the results of XRD analysis of simple material.

\section{CURRENT KNOWLEDGE FOR UNDERSTANDING XRD ANALYSIS}

\subsection{Basic Principle of XRD Instrument}

The basic principle of XRD is $x$-rays shotted into a sample of crystalline solids, then diffract the rays in all directions according to Bragg's Law. The detector moves at a constant angular velocity to detect the X-ray beam diffracted by the sample. Powder samples or crystalline solids have lattice planes arranged randomly with various possible orientations. The X-ray diffraction obtained is a typical diffraction pattern of the material. Figure 1 illustrated the basic principle of XRD. 


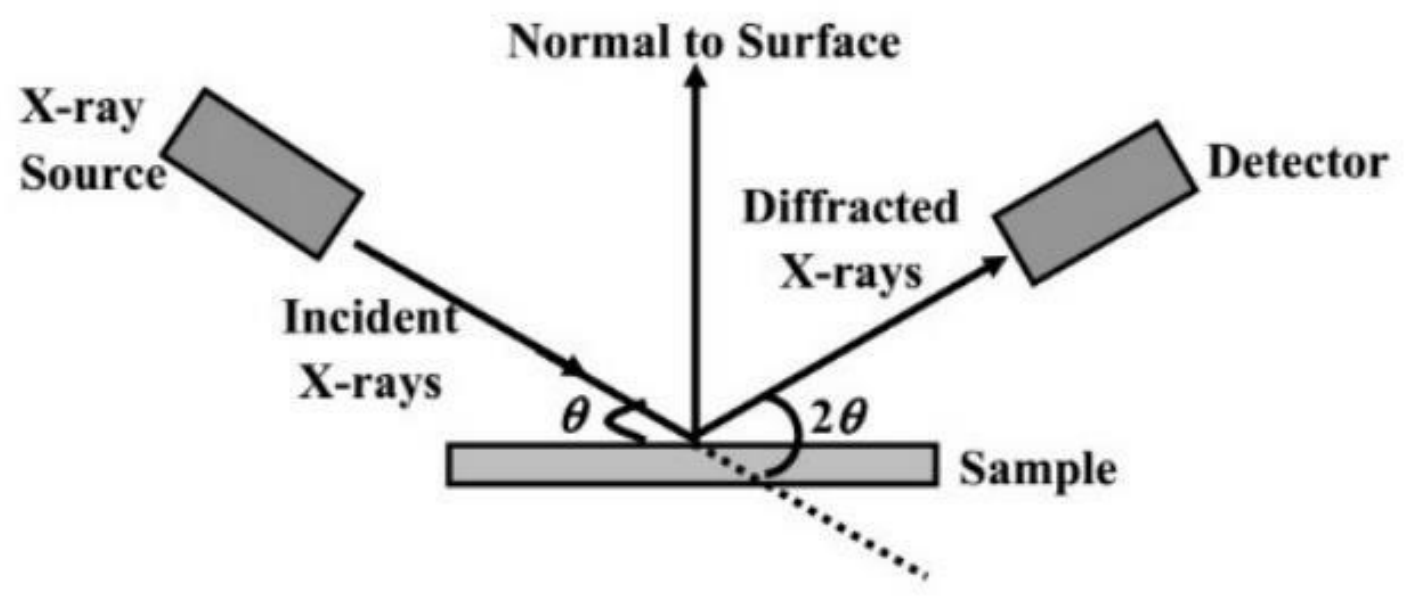

Figure 1. Illustration of basic principle of XRD.

In Figure 1, the incident ray has an angle $(\theta)$ with a distance of $d$ which makes the path lengths between the different light paths. This causes constructive wave interference, this phenomenon can be analyzed by the Bragg equation (Stobinski et al., 2014). The Bragg equation follows Equation [1] as follows:

$2 d_{\mathrm{hkl}} \sin \theta=n \lambda$

where $n$ is diffraction order $(1,2,3$, and so on), $d$ is the distance between planes of atoms in the crystal (plane with a certain Miller index), $\theta$ is the diffraction angle, and $\lambda$ is the wavelength of the X-rays used.

The resulting diffractogram pattern is in the form of a row of diffraction peaks reaction with relative intensity varies along with a certain value of $2 \vartheta$. The relative intensity of the series of peaks depends on the number of atoms or ions and their distribution within the unit cell of the material. The diffraction pattern of each crystalline solid is very distinctive, which depends on the crystal lattice, the parameter units, and the X-ray wavelength used. Thus, it is very unlikely that the same diffraction pattern will be produced for a different crystalline solid

\subsection{Analysis Qualitative in Determining of Crystal Phase using XRD}

It has been previously mentioned that the results of the analysis with XRD are in the form of a diffractogram in the form of a line or peak with different intensities and positions that are specific to the material being used analyzed. Each crystalline phase has a diffractogram which is characteristic, then it can be used as a fingerprint for test identification (Zhong \& Jiang, 2009). The steps of qualitative analysis using XRD are as follows:

i) Step 1: Identify the diffractogram pattern

The diffractogram pattern generated from the XRD instrument is in the form of an image containing the $\mathrm{X}$-axis and $\mathrm{Y}$-axis. The axis is a row of diffraction peaks with varying relative intensity (located on the $Y$-axis) along with a certain $2 \theta$ value (located on the $X$-axis).

ii) Step 1: Determination of suitability crystal phase structure through identification of diffraction peak sharpness

Determination and comparison of suitability crystal structure formed done by matching each the peak that appears on diffractogram at angle values $2 \vartheta$ with data from JCPDS (Joint Committee Powder Standard Diffraction) thus field orientation information obtained crystals formed. If all sample crystal plane orientations have similar XRD diffraction trends or patterns which is similar to the material in the JCPDS reference, then the identified 
sample is the same as the material in the reference. In addition, there is an easy way to determine whether the material being characterized is structural or amorphous. The easy way is to identify the sharpness of the resulting peaks. If the peak is sharp, the analyzed material has a crystal structure. However, if the resulting peaks have peaks that are not sharp, then the analyzed material has an amorphous structure. Figure 2 illustrate crystalline and amorphous area in x-ray diffraction.

\subsection{Analysis Quantitative in Determination of Crystallite Size with XRD}

X-ray diffraction can be used to determine the size of crystal (crystallite size) with phase certain [3]. The determination refers to the main peaks of the pattern diffractogram through approach Debye Scherrer's equation formulated in Equation [2].

$D=\frac{\mathrm{K} \cdot \lambda}{\beta \cos \theta}$

where $D$ is the crystallite size, $K$ is the Scherrer constant (0.9), $\lambda$ is the wavelength of the $X$ rays used $(0.15406 \mathrm{~nm}), \beta$ is the Full Width at Half Maximum (FWHM, radians), and $\theta$ is the peak position (radians).

The steps for identifying crystal size using XRD are as follows:

1) Step 1: Identify the $K$ value

2) Step 2: Identify the $\lambda$ value

3) Step 3: Identify FWHM ( $\beta)$

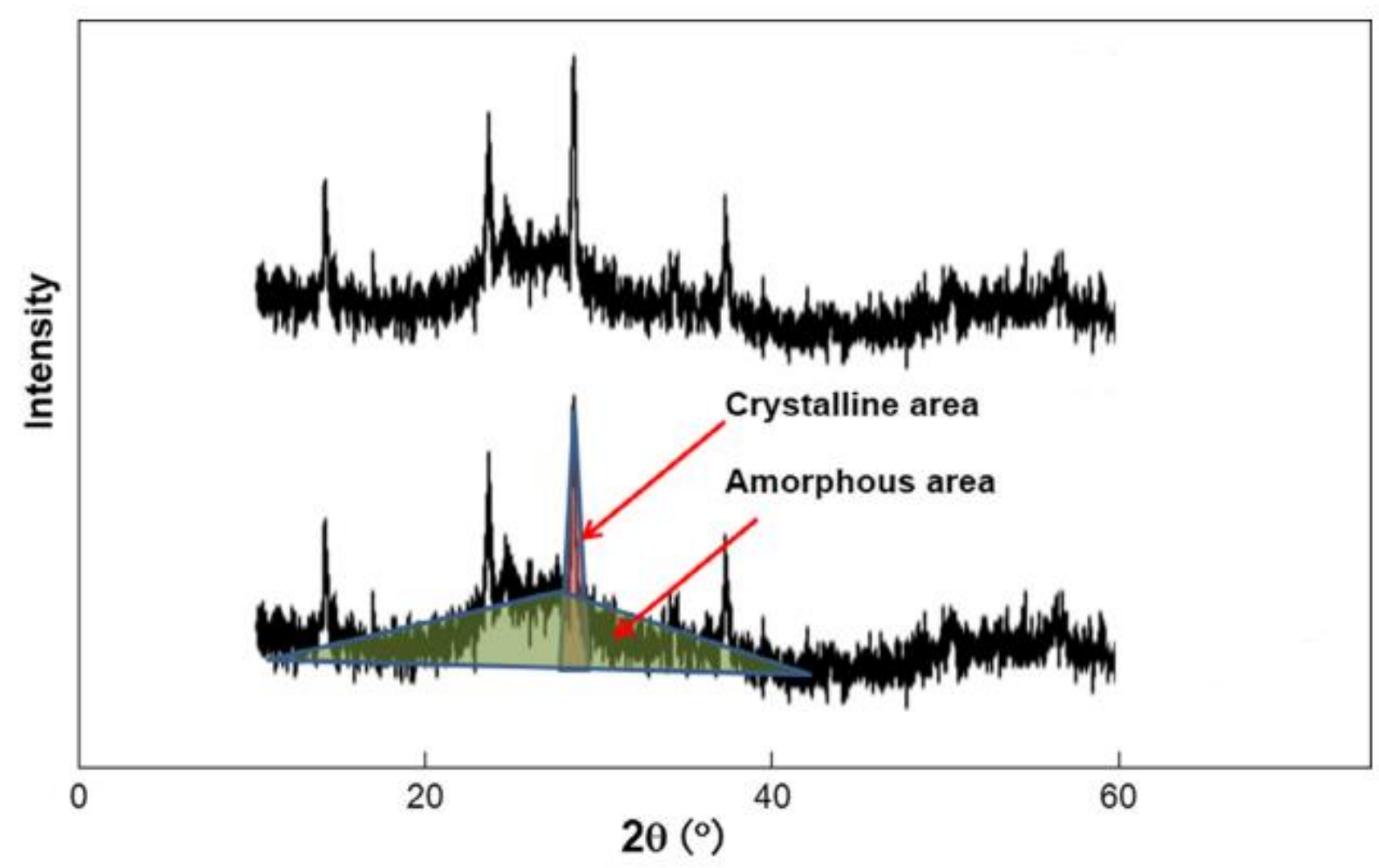

Figure 2. Illustration of crystalline and amorphous area. The figure was adopted from Nandiyanto et al., (2020). 
69 | ASEAN Journal of Science and Engineering, Volume 2 Issue 1, March 2022 Hal 65-76

To determine the value of FWHM ( $\beta$ ) can be done using the following ways:

i) Step 1: Identify the sharpest peak or crystalline area in the diffraction pattern generated by XRD

ii) Step 2: Determine the value of $2 \theta$ at the peak with the maximum intensity of the XRD diffraction pattern. Figure $\mathbf{3}$ shows a peak at the maximum intensity with certain $2 \theta$

iii) Step 3: Determine the value of half of the maximum peak intensity. Figure 4 illustrate half of the maximum peak intensity

iv) Step 4: Determine the minimum $2 \theta$ value and the maximum $2 \theta$ value at half the maximum intensity of the peak. Figure 5 illustrates the minimum $2 \theta$ value and the maximum $2 \theta$ value at half the maximum intensity.

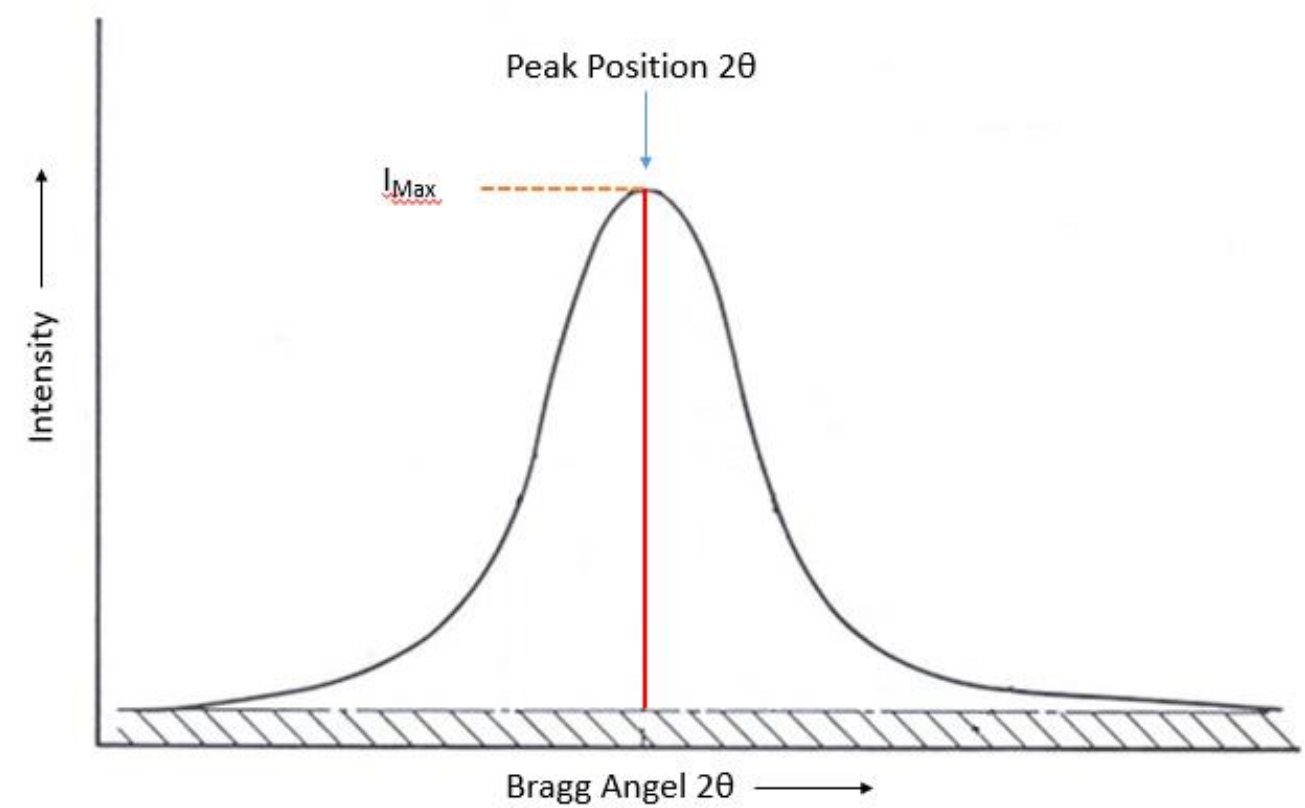

Figure 3. The peak at the maximum intensity with certain $2 \theta$.

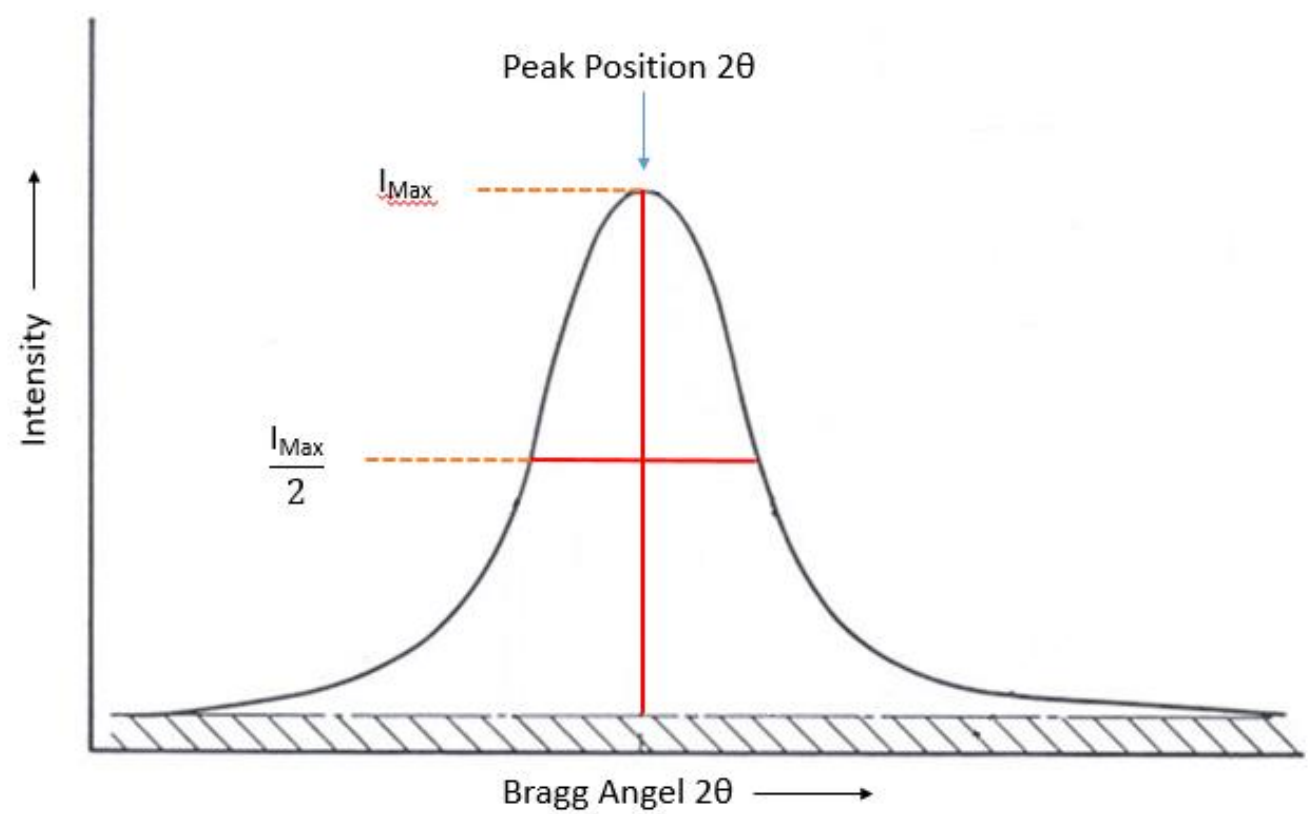

Figure 4. Illustration of half the maximum peak intensity. 


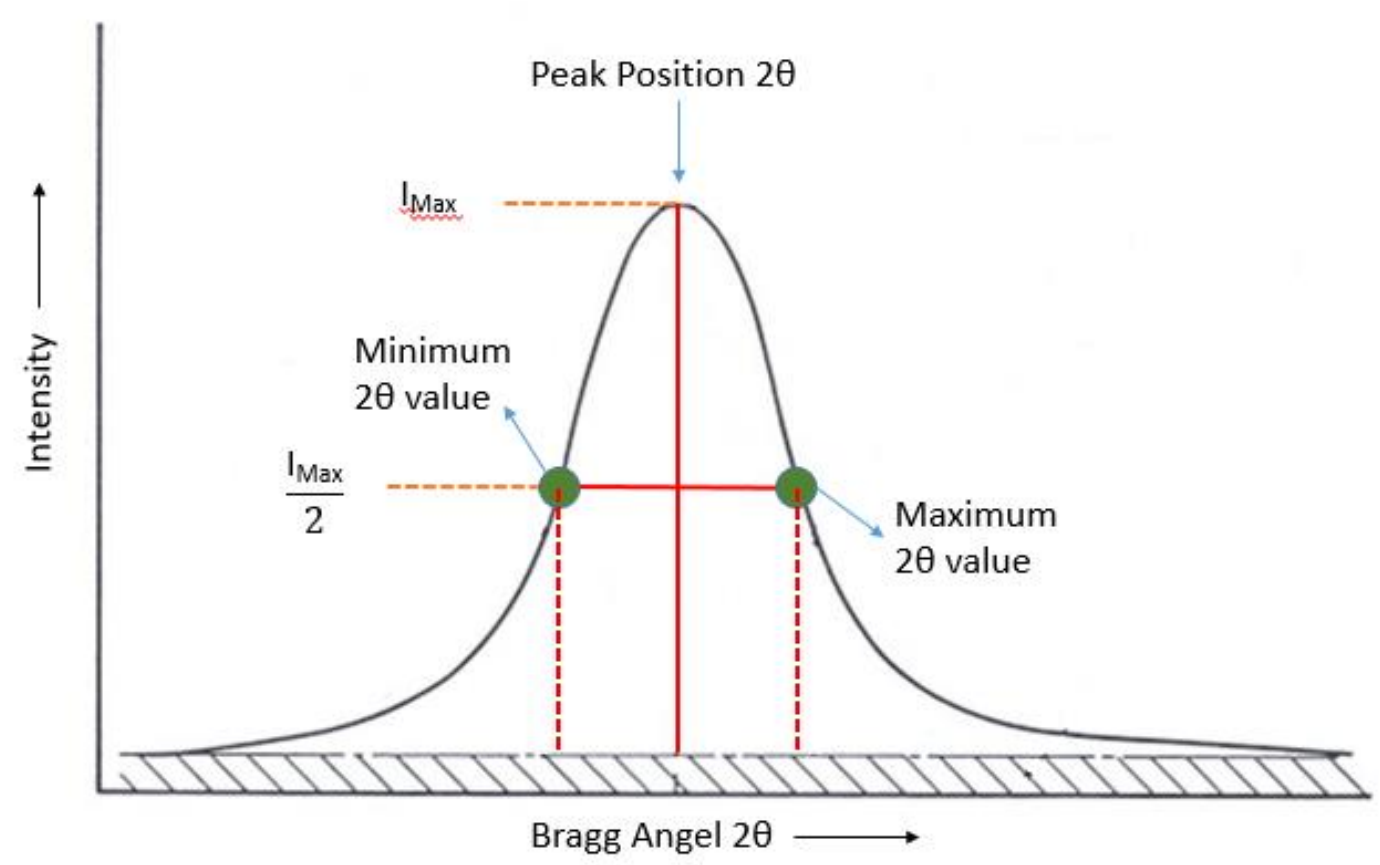

Figure 5. Illustration of minimum $2 \theta$ value and the maximum $2 \theta$ value at half the maximum intensity.

v) Step 5: Determine the FWHM $(\beta)$ value using Equation [3].

$$
\beta=\frac{1}{2}\left(2 \theta_{\text {max }}-2 \theta_{\text {min }}\right)
$$

4) Step 4: Determine the value of $\cos \theta$ from the value of $2 \theta$ value

The steps to determine the value of cos from the value of $2 \theta$ are as follows:

vi) Step 1: Divide the value of $2 \theta$ theta by the number 2 thus $\theta$ is known

vii)Step 2: Change $\theta$ value to $\cos \theta$

5) Step 5: After all the values from step 1 to step 4 are known, the last step is to put these values in Equation [2] so that the crystal size is obtained.

In short, by performing a curve selection of the diffraction peaks of each plane crystal at position $2 \theta$, we can see half-peak curve widening value diffraction (FWHM), then with a value of is put into the equation Scherrer to determine the size crystal.

\section{EXPERIMENTAL METHOD}

To understand how to interpret the results of XRD analysis, this study is equipped with a way of explaining how qualitative analysis is to determine the crystal phase and quantitative analysis to determine crystallite size. A detailed step-by-step approach to XRD analysis is described in this study.

Several studies that have been published are discussed in this study, especially regarding the discussion of XRD analysis. For qualitative analysis using XRD, we adopt and discuss the XRD results from studies published by Nandiyanto et al., (2020). For quantitative analysis, we adopt a study from Zulkani and Joniwarta, (2020). A study published by Nandiyanto et al., (2020) describes the amorphous content of micrometer-sized tungsten trioxide particles. A study published by Zulkarnain \& Joniwarta, (2020) describes barium hexaferrite (BHF) material that was prepared by the mechanical alloying method. 
71 | ASEAN Journal of Science and Engineering, Volume 2 Issue 1, March 2022 Hal 65-76

\section{RESULTS AND DISCUSSION}

\subsection{Qualitative Analysis using XRD}

Figure 6 shows the XRD spectra of micrometer-sized tungsten trioxide particles. To understand the appearance peaks in the XRD below, a step-by-step process can be used. The results can be concluded as follows:

1) Step 1: Identify the diffractogram pattern

From the XRD spectrum adopted from Nandiyanto et al., (2020), there are monoclinic and hexagonal $\mathrm{WO}_{3}$ particles spectra from the JCPDS reference. The other spectra are $\mathrm{WO}_{3}$ particle spectra which have been successfully synthesized by calcination at 235 to $320^{\circ} \mathrm{C}$. $\mathrm{WO}_{3}$ particles has different amorphous percentages $(0,8,20,22,40,60,75,90$, and $100 \%$ ) with different peaks.

2) Step 2: Based on step 1, several WO3 particle peaks have been prepared according to the reference peaks in the JCPDS. $\mathrm{WO}_{3}$ particles calcined at a temperature of $235^{\circ} \mathrm{C}$ have a non-sharp XRD peak than the other XRD peaks. $\mathrm{WO}_{3}$ particles calcined at a temperature of $245-300^{\circ} \mathrm{C}$ have peaks that match with the JCPDS reference for hexagonal $\mathrm{WO}_{3}$ particles phase. Meanwhile, $\mathrm{WO}_{3}$ particles calcined at a temperature of $320^{\circ} \mathrm{C}$ has sharp peak and its peaks match with the JCPDS reference for the monoclinic $\mathrm{WO}_{3}$ particles phase. However, $\mathrm{WO}_{3}$ particles hexagonal phase that calcined at a temperature of 245$300^{\circ} \mathrm{C}$ has a different peak intensity. This difference in intensity is related to the sharpness of the XRD peak, which corresponds to the crystalline phase of the sample. Samples with sharp peaks show a high crystalline phase and the sample with a less sharp peak showed a high amorphous phase.

Based on the above analysis, the analysis shows that the $\mathrm{WO}_{3}$ particles that have been calcined at a temperature of $235^{\circ} \mathrm{C}$ have an amorphous phase. $\mathrm{WO}_{3}$ particles calcined at a temperature of $245-300^{\circ} \mathrm{C}$ have a hexagonal crystal system with different amorphous percentages. The sharpest peak is $\mathrm{WO}_{3}$ particles with high crystallinity. Meanwhile, $\mathrm{WO}_{3}$ particles calcined at a temperature of $320^{\circ} \mathrm{C}$ have a monoclinic crystal system with high crystallinity. The trend pattern of the $\mathrm{WO}_{3}$ particle was prepared that is similar to the reference pattern in JCPDS both with monoclinic and hexagonal crystal systems indicates the success of $\mathrm{WO}_{3}$ particle synthesis. 


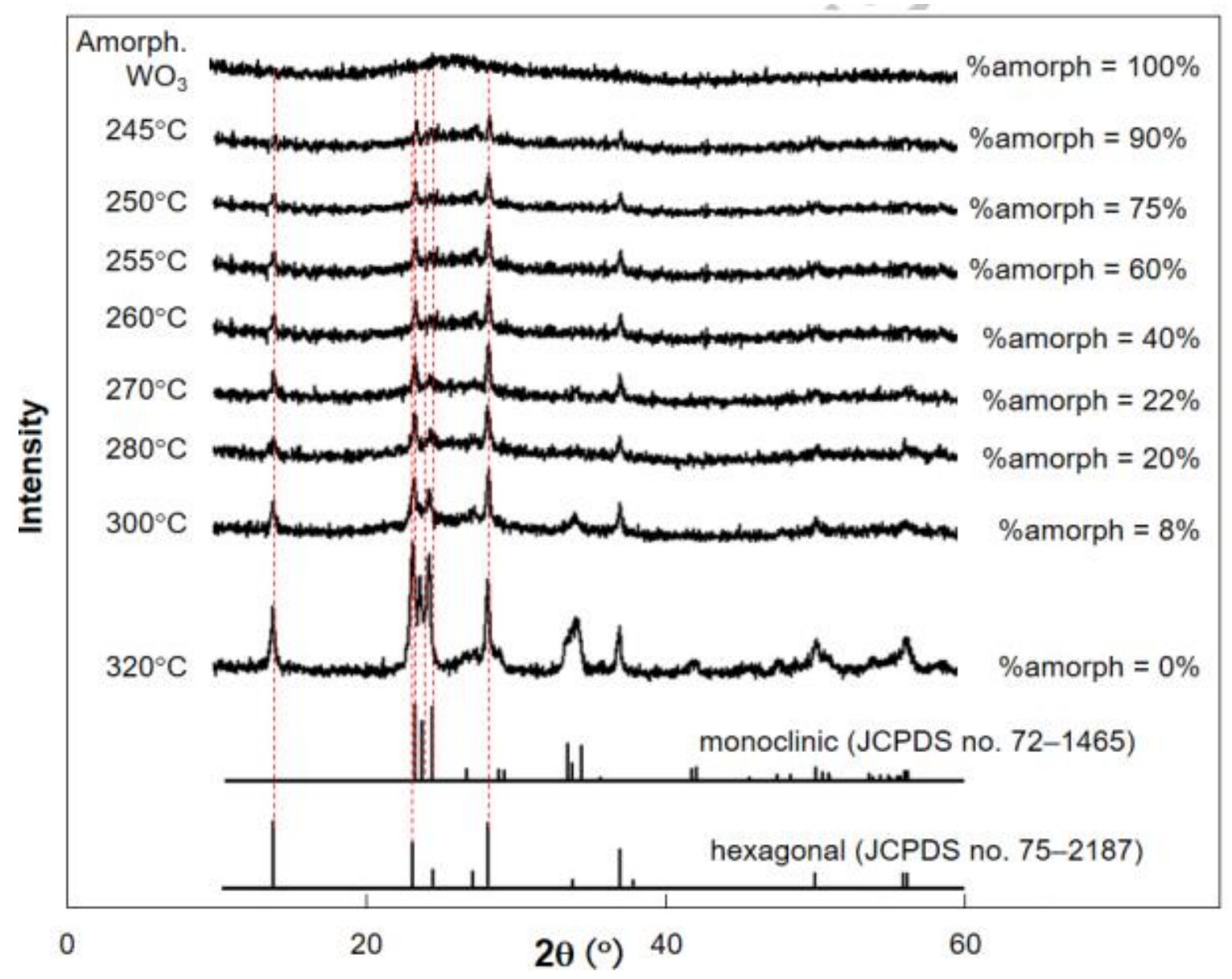

Figure 6. Example of XRD spectra of amorphous $\mathrm{WO}_{3}$ calcined from 235 to $320^{\circ} \mathrm{C}$. The figure was adopted from Nandiyanto et al., (2020).

\subsection{Quantitative Analysis}

Figures $\mathbf{7}$ ( $\mathbf{a}$ and $\mathbf{b}$ ) are the result of XRD characterization of prepared BHF material and $X R D$ result of reference BHF. Based on the qualitative analysis, namely the determination and comparison of the suitability of the crystal phase structure, the results of the XRD characterization of the synthesized BHF material showed compatibility with the reference BHF material. This means that the BHF material has been successfully synthesized.

To determine the crystal size prepared BHF material using the equation Scherrer in Equation [2], perform the following steps:

1) Step 1: $K$ value is 0.9

2) Step 2: $\lambda$ is the wavelength of the $X$-rays used $(0.15406 \mathrm{~nm})$

3) Step 3: To get the FWHM $(\beta)$ value, the following analytical steps are carried out:

i) The crystalline peaks in the prepared BHF material are at $2 \theta \geq 30^{\circ}(2 \theta=35.4 ; 37.56$; and $39.87^{\circ}$ ).

ii) Figures 8, 9, and $\mathbf{1 0}$ are a half-peak curve widening value diffraction (FWHM) for $2 \theta=$ 35.40; 37.56; and $39.86^{\circ}$.

4) Tabel 1 is summarize $\operatorname{Cos} \theta$ value from $2 \theta=35.40 ; 37.56$; and $39.86^{\circ}$.

5) Table 2 summarizes the crystal sizes obtained from Equation [2].

From the results of calculations using the Scherrer equation in Equation [2], the size of the prepared BHF crystal is about $73.18 \mathrm{~nm}$. 
73 | ASEAN Journal of Science and Engineering, Volume 2 Issue 1, March 2022 Hal 65-76

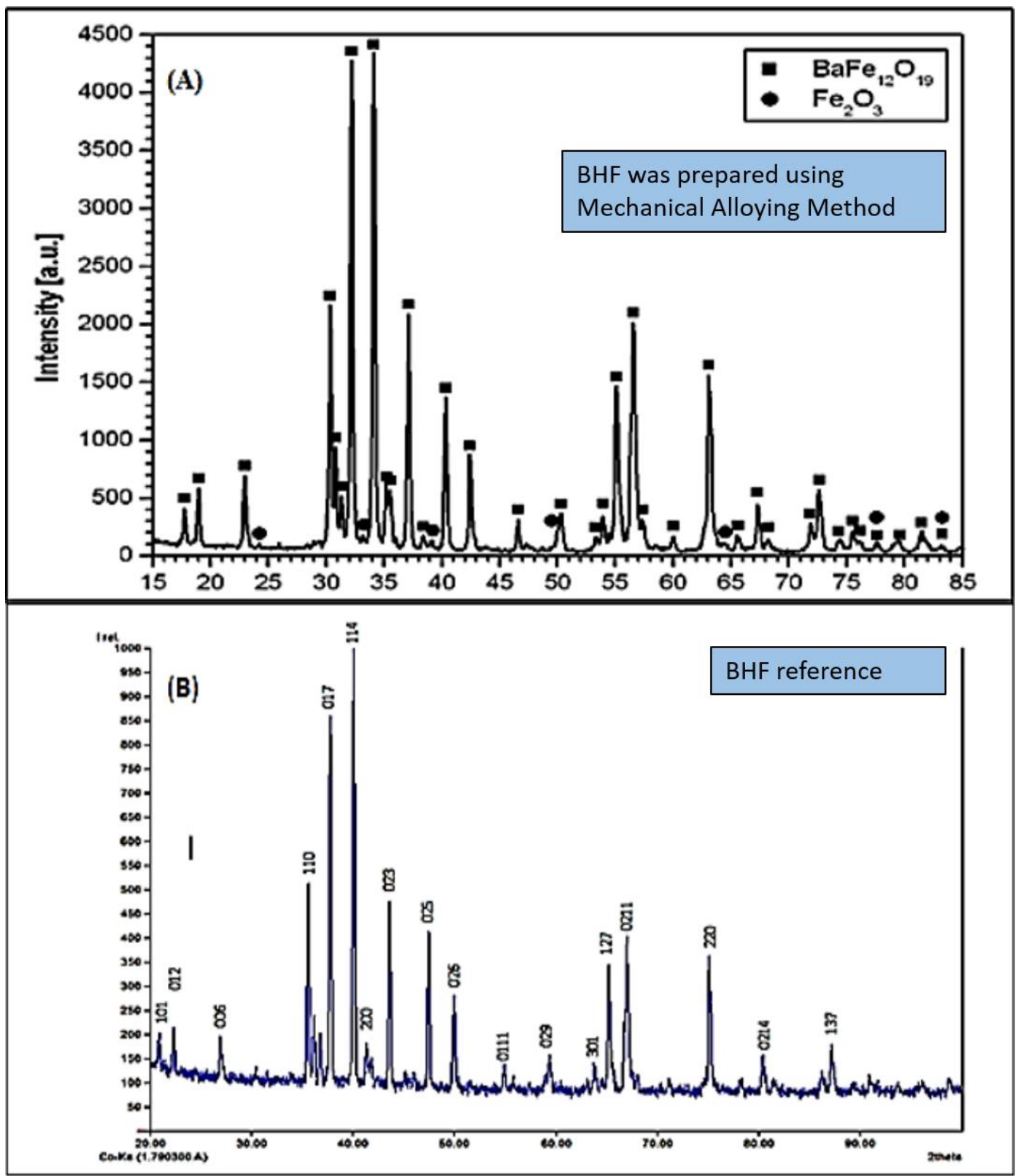

Figure 7. X-ray diffraction of prepared BHF and x-ray diffraction of reference BHF. The figure was adopted from Zulkarnain and Joniwarta (2020).

Table 1. $\operatorname{Cos} \theta$ value from $2 \theta=35.40 ; 37.56$; and $39.86^{\circ}$.

\begin{tabular}{lll}
\hline $\mathbf{2 \theta}\left(^{\circ}\right)$ & $\boldsymbol{\theta}\left(^{\circ}\right)$ & $\boldsymbol{C o s} \boldsymbol{\theta}$ \\
\hline 35.40 & 17.70 & 0.952 \\
37.56 & 18.78 & 0.946 \\
39.86 & 19.33 & 0.944 \\
\hline
\end{tabular}

Table 2. The results of the calculation of the crystal size on the BHF diffraction peak.

\begin{tabular}{ccccccc}
\hline $\mathbf{2 \theta}\left(\mathbf{(}^{\circ}\right)$ & $\operatorname{Cos} \boldsymbol{\theta}$ & $\boldsymbol{K}\left(\mathbf{r a d} . \dot{\mathbf{A}}^{-2}\right)$ & $\boldsymbol{\lambda}(\mathbf{n m})$ & $\begin{array}{c}\text { FWHM } \\
(\boldsymbol{\beta})\left(^{\circ}\right)\end{array}$ & $\begin{array}{c}\text { FWHM } \\
(\boldsymbol{\beta})(\mathbf{r a d})\end{array}$ & $\begin{array}{c}\text { Crystallite Size } \\
(\mathbf{n m})\end{array}$ \\
\hline 35.40 & 0.952 & 0.9 & 0.15406 & 0.110 & 0.002 & 72.82 \\
37.56 & 0.946 & 0.9 & 0.15406 & 0.105 & 0.002 & 73.28 \\
39.86 & 0.944 & 0.9 & 0.15406 & 0.105 & 0.002 & 73.44 \\
& & & & \\
& Average Size $(\mathbf{n m})$ & & & \\
\hline
\end{tabular}




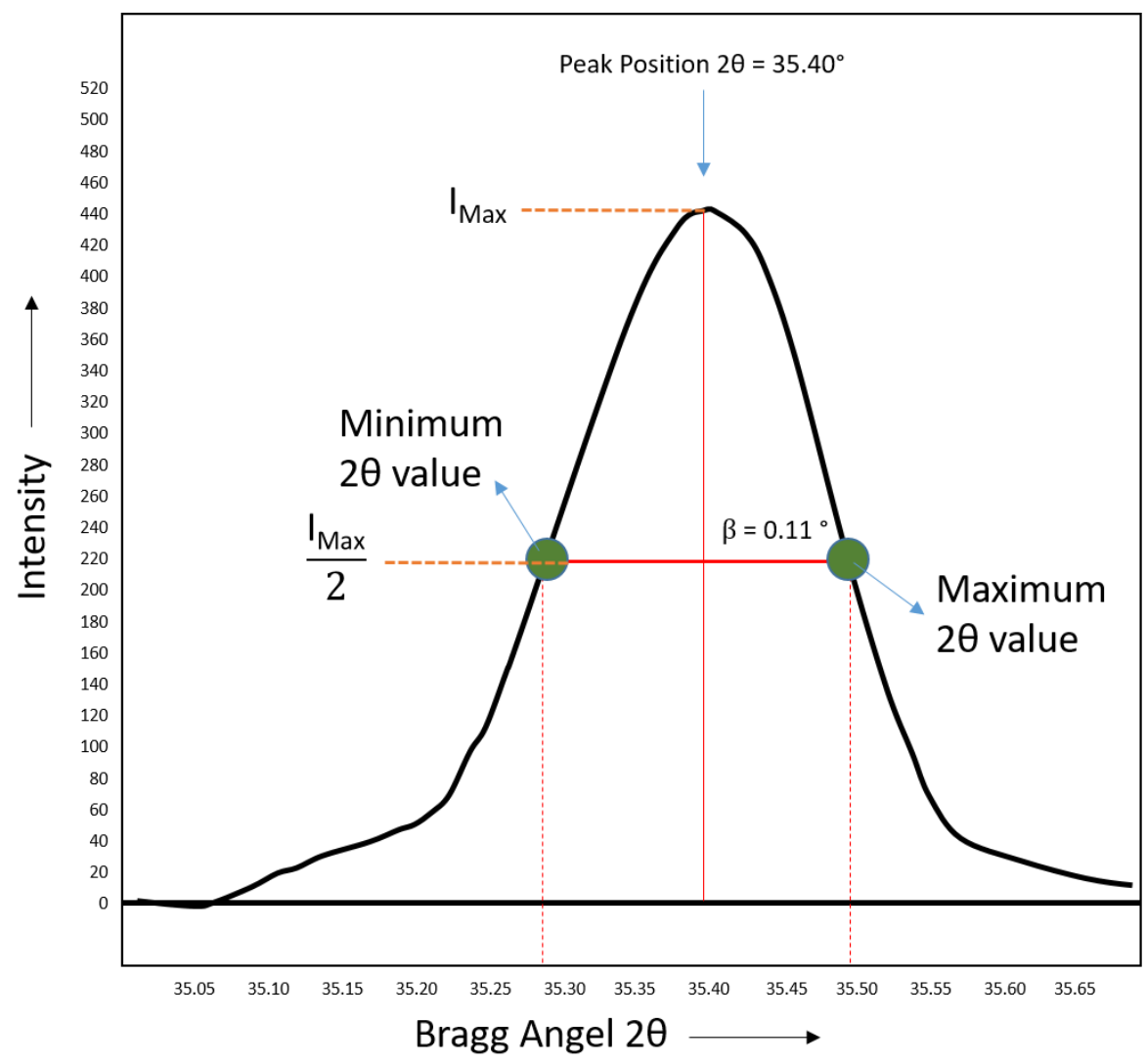

Figure 8. A half-peak curve widening value diffraction (FWHM) for $2 \theta=35.4^{\circ}$. The figure was adopted from Zulkarnain and Joniwarta (2020).

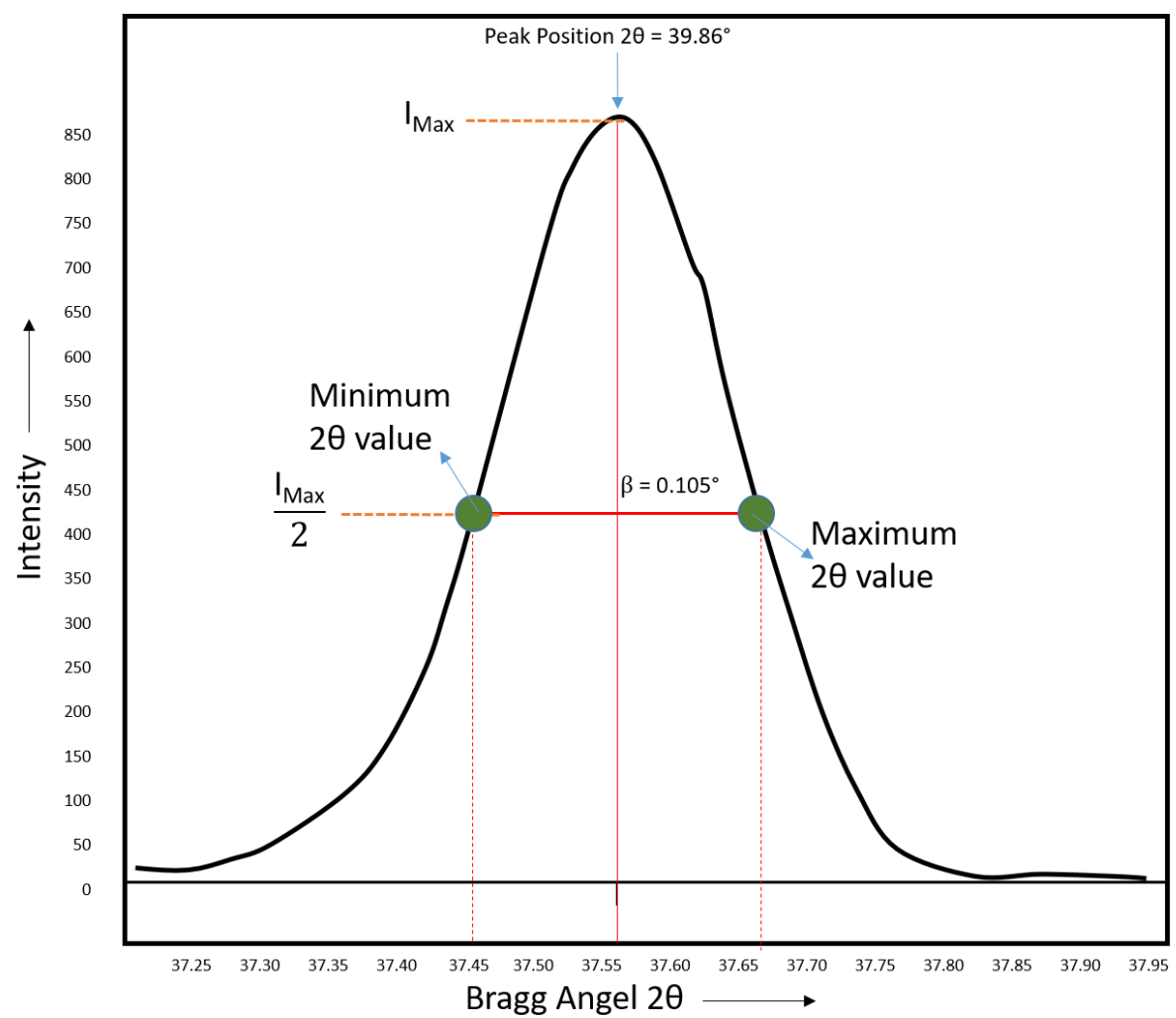

Figure 9. A half-peak curve widening value diffraction (FWHM) for $2 \theta=37.56^{\circ}$. The figure was adopted from: Zulkarnain and Joniwarta (2020). 
75 | ASEAN Journal of Science and Engineering, Volume 2 Issue 1, March 2022 Hal 65-76

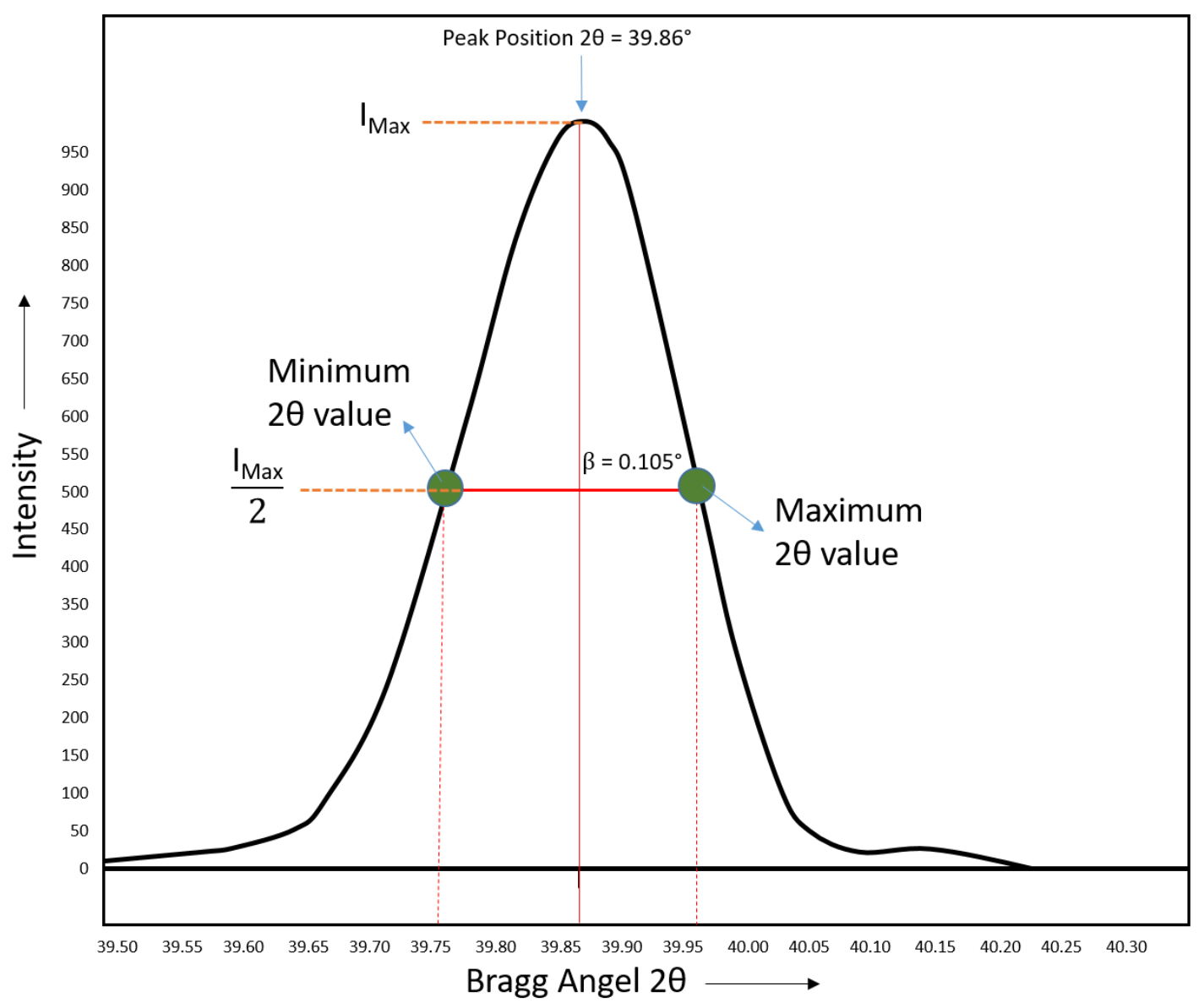

Figure 10. A half-peak curve widening value diffraction (FWHM) for $2 \theta=39.86^{\circ}$. The figure was adopted from Zulkarnain and Joniwarta (2020).

\section{CONCLUSION}

This study describes an easy and detailed way of qualitative (determining the phase of the sample crystal) and quantitative (determining the size of the sample crystallite) of the spectra produced by the $x$-ray diffraction instrument. This study was also tested for the analysis of $\mathrm{WO}_{3}$ particles and barium hexaferrite particles.

\section{AUTHORS' NOTE}

The authors declare that there is no conflict of interest regarding the publication of this article. The authors confirmed that the paper was free of plagiarism.

\section{REFERENCES}

Alexander, L., and Klug, H. P. (1948). Basic aspects of X-ray absorption in quantitative diffraction analysis of powder mixtures. Analytical Chemistry, 20(10), 886-889.

Bunaciu, A. A., UdrişTioiu, E. G., and Aboul-Enein, H. Y. (2015). X-ray diffraction: Instrumentation and applications. Critical Reviews in Analytical Chemistry, 45(4), 289299. 
Hakim, L., Dirgantara, M., and Nawir, M. (2019). Karakterisasi struktur material pasir bongkahan galian golongan $\mathrm{c}$ dengan menggunakan X-Ray Difraction (X-RD) di kota Palangkaraya. Jurnal Jejaring Matematika dan Sains, 1(1), 44-51.

Monshi, A., Foroughi, M. R., and Monshi, M. R. (2012). Modified Scherrer equation to estimate more accurately nano-crystallite size using XRD. World Journal of Nano Science and Engineering, 2(3), 154-160.

Nandiyanto, A. B. D., Oktiani, R., Ragadhita, R., Sukmafitri, A., and Zaen, R. (2020). Amorphous content on the photocatalytic performance of micrometer-sized tungsten trioxide particles. Arabian Journal of Chemistry, 13(1), 2912-2924.

Saini, I., Rozra, J., Chandak, N., Aggarwal, S., Sharma, P. K., and Sharma, A. (2013). Tailoring of electrical, optical and structural properties of PVA by addition of Ag nanoparticles. Materials Chemistry and Physics, 139(2-3), 802-810.

Smith, D. K., Johnson, G. G., Scheible, A., Wims, A. M., Johnson, J. L., and Ullmann, G. (1987). Quantitative X-ray powder diffraction method using the full diffraction pattern. Powder Diffraction, 2(2), 73-77.

Stobinski, L., Lesiak, B., Malolepszy, A., Mazurkiewicz, M., Mierzwa, B., Zemek, J., and Bieloshapka, I. (2014). Graphene oxide and reduced graphene oxide studied by the XRD, TEM and electron spectroscopy methods. Journal of Electron Spectroscopy and Related Phenomena, 195, 145-154.

Zhong, X. K., Li, D. C., and Jiang, J. G. (2009). Identification and quality control of Chinese medicine based on the fingerprint techniques. Current Medicinal Chemistry, 16(23), 3064-3075.

Zhou, X., Liu, D., Bu, H., Deng, L., Liu, H., Yuan, P., and Song, H. (2018). XRD-based quantitative analysis of clay minerals using reference intensity ratios, mineral intensity factors, Rietveld, and full pattern summation methods: A critical review. Solid Earth Sciences, 3(1), 16-29.

Zulkani Sinaga, Z. S., and Joni Warta, J. W. (2020). Analisis ukuran kristal dan sifat magnetik melalui proses pemesinan milling menggunakan metode karakterisasi Xrd, mechannical alloying, dan ultrasonik tekanan tinggi pada material barium hexaferrite (Bafe12o19). Jurnal Kajian Teknik Mesin (JKTM), 5(1), 1-6. 